\title{
Letter to Editor:
}

\author{
Response to "Knowledge, Attitude, and Practice Regarding Dengue among Students in a Public \\ University in Malaysia" \\ Michael White
}

Bangladesh Journal of Medical Science Vol. 19 No. 04 October'20. Page : 775-777 DOI: https://doi.org/10.3329/bjms.v19i4.46642

The original article titled "Knowledge, Attitude, and Practice Regarding Dengue among Students in a Public University in Malaysia" was recently published in this journal in Vol. 19 No. 02 ${ }^{1}$. The authors developed an instrument with four sections to measure knowledge, attitude, and practice (KAP) regarding dengue among students at their university, the International Islamic University of Malaysia (IIUM) Kuantan. Dengue is undoubtedly an important topic, and studies related to KAP could contribute to improving practices and lowering spread and mortality rates of this virus. Thus the study is admirable due to is relevance and importance. However, the methodology provides incomplete information, the sample size focuses only on generalizability of results within the target university, the scoring system leads to certain measuring errors, and key validation information for the survey instrument is lacking.

Although the materials and methods section of this article details the composition of the survey instrument, there is very little information given about its development and validation. The following two sentences are the only explanation regarding the pilot study and instrument development: "The pilot study was conducted before the actual study to test for the reliability and face validity of the research methods and questionnaires. The content validity was verified by an expert." "Although the article includes a presentation of a conceptual framework, no mention is made of how the questions were developed, the sample size for the pilot study, the statistical analysis used to validate the survey instrument in the pilot study, nor the results of this statistical analysis. Instrument development and validation should follow a process of item pool formation and item refinement which generally includes exploratory factor analysis ${ }^{2}$. It is likely that the authors followed such a process, but it should have been explained in the article. Furthermore, mention is made of only one expert who reviewed the questions, but ideally instrument development should include an approach like the Delphi Technique so as to include the expert review of several judges and the criteria used to select these judges should be presented ${ }^{3}$. Additional experts should have been consulted and more information should have been given regarding the expert review process.

This study used a sample of 135 students, based on a formula considering the target university, the IIUM Kuantan, as the single population. While it is certainly important to study the university, and it is a good starting point, the results are not necessarily generalizable beyond the target university. The study can still contribute important information as a single site case study, but the results and discussion should be carefully framed to avoid overgeneralizing the results based on the limited population.

The survey instrument includes three sections which were scored and one section with socio-demographic information. Although the scoring procedure is well described in the article, the justification is lacking. The last two sections use a 5 point and 4 point Likert scale respectively for attitudes and practices, and summary statistics are given. While additional statistics could provide additional evidence for the validity of this scoring system, it is at least feasible. The questions about knowledge of dengue, however, consist of 31 items with response options of true/ don't know/false. The correct answer receives 2 points and a wrong answer receives 0 points, but an answer of don't know receives 1 point. Since there are 31 questions in this section, if a participant did not know any of the answers and marked don't know for every item, they would receive a score of 31 , which would fall into the Moderate category of 21-41 according to the scoring guide. The only way to receive a Poor score would be to answer questions incorrectly. Not surprisingly, the results section describes how none

Correspondence to: Michael White, M. Div. Head of Scientific Publications and Translations, Dirección General de Investigación, Universidad Peruana Unión, Lima, Peru

Author ORCID: https://orcid.org/0000-0003-4530-8167 Email: michaelwhite@upeu.edu.pe 
of the participants received a score of Poor and $97.8 \%$ received a score of Good, which includes the range of scores from 42-62. To reach the minimum score of 42 to enter in the category of Good, a participant could answer 20 questions with don't know (granting 20 points) and answer only 11 questions correctly (granting 22 points). Although this assumes that the participant does not answer any questions incorrectly, correctly answering 11 out of 31 questions is only a $35.5 \%$ correct answer rate and is thus questionable as the minimum score for the highest score category. Based on the $97.8 \%$ rate of participants who entered in the Good category, the authors should have noted this discrepancy and reevaluated the scoring system and categories for this part of the survey instrument. Finally, this study is based on a survey instrument which was apparently designed and applied by the authors, but the statistical analyses presented largely focus on correlations between factors rather than on the validity of the survey instrument. No mention is made of factorial analysis, internal consistency, nor convergent nor divergent validity. Commonly used statistical measures like Cronbach's Alpha, factorial loadings, and even standardized root mean squared residual (SRMR) could have been included because the authors should always provide evidence for the validity of the survey instrument ${ }^{4}$.

In conclusion, the concern and effort of the authors is laudable based on the gravity of the topic of study, namely, dengue. A survey instrument to measure KAP regarding dengue would be a useful tool for future studies, and the attempt to develop and apply such an instrument in this study is admirable. However, the validity and generalizability of both the survey instrument and its results are questionable based on methodological concerns. The authors should publish more information about the development and validation process of their instrument, and furthermore they should publish the full instrument so that other researchers can apply it in different populations and provide additional evidence of its validity.

\section{$\underline{\text { References }}$}

1. Zamri SNZBM, Rahman NAA, Haque M. Knowledge, Attitude, and Practice Regarding Dengue among Students in a Public University in Malaysia. Bangladesh J Med Sci. 2020 Jan 16;19(2):245-53.

2. Kline P. An Easy Guide to Factor Analysis. London: Routledge; 2014. 209 p.

3. Jünger S, Payne SA, Brine J, Radbruch L, Brearley SG. Guidance on Conducting and REporting
DElphi Studies (CREDES) in palliative care: Recommendations based on a methodological systematic review. Palliat Med [Internet]. 2017 Sep 13 [cited 2020 Feb 21];31(8):684-706. Available from: http://www.ncbi.nlm.nih.gov/ pubmed/28190381

4. Hair JF, Babin BJ, Anderson RE, Black WC. Multivariate Data Analysis. 8th ed. London: Cengage Learning EMEA; 2018. 832 p.

\section{Authors Response}

White M, Head of Scientific Publications and Translations, Dirección General de Investigación, Universidad Peruana Unión, Lima, Peru, towards Knowledge, Attitude, and Practice Regarding Dengue among Students in a Public University in Malaysia. Bangladesh Journal of Medical Science 2020; 19 (2): 245-253. https://doi.org/10.3329/bjms.v19i2.45003

Siti Nur Zubaidah Binti Mohamad Zamri ${ }^{1}$, Nor Azlina a Rahman ${ }^{1}$, Mainul Haque ${ }^{2}$

1. Department of Physical Rehabilitation Sciences, Faculty ofAllied Health Sciences, International Islamic University Malaysia, 25200 Kuantan, Malaysia.

2. Faculty of Medicine and Defence Health, Universiti Pertahanan Nasional Malaysia (National Defence University of Malaysia), Kem Sungai Besi, 57000 Kuala Lumpur, Malaysia. Land Line: +60 39051 3400 Ext 2257 (Office). +60 361795871 (Home). Cell Phone: + 6010926 5543. Email: runurono@, gmail.com. Orcid ID: http://orcid.org.0000-0002$\underline{6124-7993}$

Dengue is a viral infectious disease transmitted by an infected female Aedes mosquito ${ }^{1,2}$. There is currently no available specific treatment for dengue. Hence severe dengue can be fatal ${ }^{1}$. The condition is more commonly found in the tropical and sub-tropical countries, where the temperature is suitable for the transmission of the disease by the Aedes mosquito ${ }^{1,2}$. An author had estimated the worldwide dengue infections of up to 390 million cases per year, which is more than triple the World Health Organization (WHO)'s dengue burden estimate ${ }^{3}$. In Malaysia, dengue was first reported on November 15, 1902, which at that time was known as Malaya, while the first severe dengue was first observed in Malaya in $1962^{4}$. Dengue has been endemic in Malaysia for many years, with outbreaks occurring from time to time in the different states in Malaysia, which predominantly occurs in the highly populated urban area $^{4}$. In view of the importance of prevention of this possibly fatal disease, a study on "Knowledge, Attitude, and Practice Regarding Dengue among 
Students in a Public University in Malaysia" was conducted, among others to create awareness regarding this disease which can be considered as a public health problem in Malaysia ${ }^{5}$. As a background, this study was undertaken to fulfill the pre-requisite for a bachelor's degree and hence was conducted by an undergraduate student. It was one of the reasons why a very high level of research standard was not set for this study, besides the limitation of the short timeframe and minimal human and financial resources faced.It is hoped that the result from this preliminary study can give us some initial information regarding the knowledge, attitude, and practice of university students regarding dengue, along with bringing more awareness to this young generation about this significant disease. Due to the limitation of the sampling method used, it was not aimed to generalize the result from this study to a more substantial population, and any misunderstanding regarding this matter is not intentional. Admittedly, only minimal validation was carried out on the research tool, namely the questionnaire, but it is hoped that if anyone is interested, they can help to validate the questionnaire further by carrying out a more prominent pilot study to check for the questionnaire's content validity using the Delphi Technique, checking its reliability in terms of Cronbach alpha, carrying out factor analysis to check the questionnaire's construct validity, or any other validation method to further improve the questionnaire $^{6}$. We are willing to share the survey instrument with any researcher who is interested to develop and use this research tool.In view of the above, it is also hoped that this study, with its inherent limitations, is able to contribute to the body of knowledge regarding dengue, which is one of the potential threat among ten diseases as listed by WHO in 2019, as observed and confirmed by the outbreaks occurred in many countries?

\section{References:}

1. World Health Organization (WHO). Dengue and Severe Dengue. WHO Fact Sheet. 2020 March 2. Available from https://www.who.int/en/news-room/fact-sheets/ detail/dengue-and-severe-dengue

2. Gill, BS. What is Dengue? MyHEALTH Kementerian Kesihatan Malaysia Portal. 2017 February 8. Available from http://denggi.myhealth.gov.my/what-is-dengue/?lang=en

3. Bhatt S, Gething PW, Brady OJ, Messina JP, Farlow

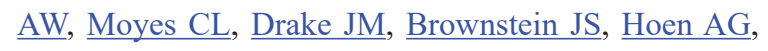

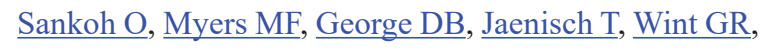

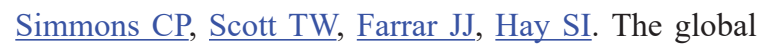
distribution and burden of dengue. Nature. 2013 April 25, 496(7446):504-7. doi: 10.1038/nature12060. Epub 2013 Apr 7

4. Gill, BS. History and Epidemiology of Dengue.
MyHEALTH Kementerian Kesihatan Malaysia Portal. 2017 February 8. Available from http://denggi.myhealth. gov.my/history-and-epidemiology-of-dengue/?lang=en

5. Zamri SNZBM, Rahman NAA, Haque M. Knowledge, attitude, and practice regarding dengue among Kuantan medical campus students of international Islamic university of Malaysia. Bangladesh J Med Sci. 2020 Jan 16;19(2):245-53

6. White M. Response to "Knowledge, Attitude, and Practice Regarding Dengue among Students in a Public University in Malaysia.”Bangladesh J Med Sci. (Letter to Editor). 2020.

7. WHO. Dengue and Severe Dengue. Health topics. 2020. Available from https://www.who.int/health-topics/ dengue-and-severe-dengue $\#$ tab $=$ tab_1 